\title{
Morphological Orthodoxy in Yupik-Inuit
}

\author{
ANTHONY C. WOODBURY \\ University of Texas, Austin
}

\section{Introduction}

Yupik-Inuit (or Eskimo) languages have one pervasive morphological process, recursive suffixation to a base, and - normally - a corollary scope rule according to which any suffix is an operator or modifier with scope over exactly the base to which it was added. This pattern is both prolific and exclusive: there is (almost) no prefixation, no mutation, ablaut, reduplication, nor any base-base or (practically any) word-word compounding. Moreover the pattern has apparently been historically persistent, since it dominates all known members of Yupik-Inuit and more distantly-related Aleut as well.

Taking this morphological 'straitjacket' as its starting point, this paper explores violations of the corollary scope rule. My point is that these scopal violations are determined by the grammatical or semantic content of individual suffixes, in keeping with the behavior associated with that content in languages with more heterodox morphology and syntax. In effect, then, the language family's orthodox morphology becomes the ground for a natural experiment, allowing us to diagnose independent and perhaps universal structural proclivities of certain common lexico-grammatical functions.

\section{A sketch of word structure}

We begin with a quick sketch of word structure - the morphological 'straightjacket' - in Cup'ik, a variety of Central Alaskan Yupik (CAY) spoken in Chevak, Alaska. The facts, as will be noted later, are similar in most detail in the rest of CAY; with a little more difference in detail in the four other Yupik languages of

\footnotetext{
* I wish to thank Leo Moses, Mary Moses, Rebecca Nayamin Kelly, John Pingayak, the late Joe Friday and many others in Chevak who have taught me what I know of Cup'ik. I gratefully acknowledge support for my work in Chevak from the National Science Foundation (grants SBR 9511856, BNS 8618271, and BNS 8217785). Many of the ideas expressed here arose in my mind in the course of informal and formal collaborations over the last three decades with my colleague and former teacher Jerry Sadock - to him, many many thanks. Big thanks too to the BLS 30 organizers for a wonderful conference. Finally, thanks for comments on this paper to Hanni Woodbury.
} 


\section{Anthony C. Woodbury}

Alaska and Russia; and with yet more difference in the Inuit-Iñupiaq continuum of Alaska, Canada, and Greenland (see Woodbury 1984 on the language family). Still, the basic suffixing-only, root-derivation-inflection pattern is uniform across the family and even includes distantly-related Aleut (Bergsland 1997).

\subsection{Inflectional suffixation: Nouns}

Grammars of Yupik-Inuit languages since Kleinschmidt (1851) are in near-total agreement on what constitutes derivation vs. inflection, so I will simply assume this distinction. This understanding is, moreover, in keeping with the contemporary view (Anderson 1982) that inflection involves morphological categories made obligatory or otherwise relevant at the phrasal level, whereas derivation does not.

Ordinary nouns are inflected, suffixally, for seven CASES indicating a range of NP argument and adjunct functions as in (1); and for three NUMBERS, as in (2): ${ }^{1}$

\section{(1) Case inflection}

$\begin{array}{lll}\text { ABSOLUTIVE } & \text { arnaq } & \text { 'the/a woman (S or definite O)' } \\ \text { RELATIVE } & \text { arna-m } & \text { 'the/a woman }(\mathrm{A}) \text { or woman's }(\mathrm{P}) \text { ', } \\ \text { MODALIS } & \text { arna-meng } & \text { 'a woman }(\mathrm{O}) \text {; from the/a woman' } \\ \text { TERMINALIS } & \text { arna-mun } & \text { 'to/for/by the/a woman' } \\ \text { LOCATIVE } & \text { arna-mi } & \text { 'at the/a woman' } \\ \text { VIALIS } & \text { arna-kun } & \text { 'via the/a woman' } \\ \text { EQUALIS } & \text { arna-tun } & \text { 'like the/a woman' }\end{array}$

(2) Number inflection

$\begin{array}{lll}\text { ABSOLUTIVE SINGULAR } & \text { arnaq } & \text { 'the/a woman' } \\ \text { ABSOLUTIVE DUAL } & \text { arna-k } & \text { 'two women' } \\ \text { ABSOLUTIVE PLURAL } & \text { arna-t } & \text { 'three or more women' }\end{array}$

In addition, nouns are marked for the PERSON-first, second, third, and reflexive-third-AND NUMBER OF THEIR POSSESSOR (P), if any. (3)-(4) show a prodrop-type pattern for possessed NPs. The possessor is in the relative case. (5) shows some sample possessive suffixes, which are treated as markers for whole bundles of information: case and number of the head (possessed) noun, plus person and number of the possessor:

(arna-m) eni-i
woman-REL.SG house-ABS.SG+3SGP
'the woman's/her house'

${ }^{1}$ These categories are also marked in a number of closed noun subclasses such as pronouns, attributive adjectives, quantifiers, and demonstratives. 
(4)
(wii)
en-ka
me.REL.SG
house-ABS.SG+1SGP
'my house'

(5)

$\begin{array}{lll}\text { Possessor inflection } & & \\ \text { ABS.SG } & \text { qayaq } & \text { 'the/a kayak' (unpossessed) } \\ \text { ABS.SG+1SGP } & \text { qaya-qa } & \text { 'my kayak' } \\ \text { ABS.PL+3SGP } & \text { qaya-i } & \text { 'his kayaks' } \\ \text { ABS.DU+3PLP } & \text { qaya-gkek } & \text { 'those two's two kayaks' } \\ \text { LOC.SG+3REFL.SGP } & \text { qaya-mini } & \text { 'in his own kayak' } \\ \text { VIAL.DU+2SGP } & \text { qaya-gpekun } & \text { 'via your two kayaks' }\end{array}$

The plusses $(+)$ in (5) are a notational convenience for expressing major divisions within category bundles. While these bundles can often be analyzed into component formatives (segmented with dashes (-)), the formatives do not always correlate one-to-one with individual category values. Thus in (6), while the first example does show a one-to-one correlation, the second shows a one-to-many correlation and the third a many-to-one correlation:

$$
\begin{array}{lll}
\text { Category bundle } & \text { Formatives } & \text { Formative values } \\
\text { VIAL.DU+2SGP } & \text {-g-pe-kun } & \text {-DU-2SGP-VIAL } \\
\text { ABS.PL+3SGP } & \text {-i- } & \text {-ABS.PL+3SGP } \\
\text { ABS.DU+3DUP } & \text {-g-ke-k } & \text {-ABS.DU-ABS.DU-3DUP }
\end{array}
$$

Given this level of entanglement, it is reasonable to assume - as my category bundle notation implies - that each bundle and its associated formative array is a single entity, and that speakers simply learn them all as a (fairly large) and partly irregular list, along lines of Anderson (1992).

\subsection{Inflectional suffixation: Verbs}

Like noun inflection, verb inflection is marked entirely suffixally. The key category is MOOD, indicating illocutionary functions for verbs heading main clauses and various subordination, adverbial, or linkage functions for verbs heading non-main clauses:

$\begin{array}{lll}\text { Mood inflection (some adverbial moods omitted) } \\ \text { INDICATIVE } & \text { tekit-uq } & \text { 's/he arrived, is arriving' } \\ \text { INTERROGATIVE } & \text { tekit-a } & \text { 's/he arrived, is arriving (in wH-Q)' } \\ \text { OPTATIVE } & \text { teki-lli } & \text { 'may s/he arrive' } \\ \text { PARTICIPLE } & \text { tekite-lria } & \text { '(surprisingly) s/he arrives, arrived' } \\ \text { APPOSITIONAL } & \text { teki-lluni } & \text { 'then s/he arrived, arrives; s/he, arriving' } \\ \text { CONSEQUENTIAL } & \text { tekic-an } & \text { 'when/hecause s/he arrived, is arriving' } \\ \text { CONCESSIVE } & \text { teki-ngraan } & \text { 'although s/he arrived, is arriving' }\end{array}$




\section{Anthony C. Woodbury}

In addition, inflection in most moods includes marking for the PERSON AND NUMBER OF THE ABSOLUTIVE-CASE INTRANSITIVE SUBJECT (S), OR OF THE RELATIVE-CASE TRANSITIVE SUBJECT (A) AND ABSOLUTIVE-CASE TRANSTIVE OBJECT (O). As in NPs, this follows the familiar pro-drop pattern, as (8)-(9) illustrate for intransitive clauses and (10)-(11) illustrate for transitive clauses:

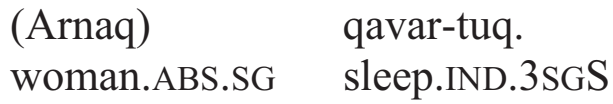

(9) (Wangkuta) qavar-tukut we.ABS.PL sleep-IND.1PLS

'We are sleeping.'

(10) (Arna-m) (kaugpii-t) tangrr-ai. woman-REL.SG walrus-ABS.PL see-IND.3SGA+3PLO 'The woman/She saw the walruses/them.'

(11) (Kaugpii-m) (wii) tangrr-aanga. walrus-REL.SG me.ABS.SG see-IND.3SGA+1SGO

'The walrus/It saw me.'

Likewise-just as in noun inflection - each verbal inflectional suffix can be seen as a single, often-irregular entity standing for a complex bundle of categories.

\subsection{Particles}

Particles are the third and final morphological class, defined by their lack of inflection. They function as adverbs and interjections, for example:

$\begin{array}{ll}\text { keyianeng } & \text { 'always' } \\ \text { unuk } & \text { 'last night' } \\ \text { cali } & \text { 'also; more' } \\ \text { tawa } & \text { 'now; then; That's enough!' } \\ \text { qa } & \text { YES-NO QUESTION MARKER; 'Huh?' } \\ \text { Kiiki! } & \text { 'Hurry up!' } \\ \text { Uuminaqsaga! } & \text { 'Darn!' }\end{array}$

\subsection{Inflectional summary}

Let us summarize the above with the following three morphological rules:

(13) Noun word = Noun base + Noun inflection

Verb word $=$ Verb base + Verb inflection

Particle word $=$ Particle base 
A WORD is thus a complete morphological entity, whereas a BASE is a word, minus its inflectional suffix. For particles, word and base are identical since there is, by definition, no inflectional suffix.

\subsection{Derivational suffixation}

Bases may be simple, but they may also be derived from other bases by recursive suffixation:

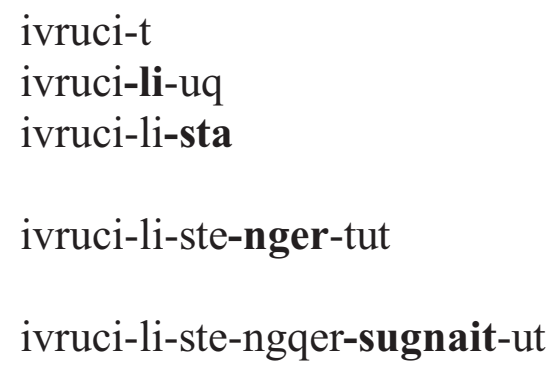

'waterboots (ABS.PL)'

'she is making waterboots (IND.3SGS)'

'someone who makes waterboots (ABS.SG)'

'they have someone who makes (them) waterboots (IND.3PLS)'

'they definitely don't have someone who makes (them) waterboots'

' $\mathrm{s} /$ he is smiling (IND.3SGS)'

' $\mathrm{s}$ /he is suddenly smiling'

's/he suddenly smiled'

' $\mathrm{s} /$ he suddenly smiled, but in vain'

'evidently s/he suddenly smiled, but in vain'

Examples (14)-(16) involve, respectively, a noun base, a verb base, and a particle base. Note that with each new round of suffixation, a new base is derived, and that new base is itself treated inflectionally either as a noun, a verb, or a particle.

\subsection{Derivational summary}

The above can be summarized with the following rule:

$$
\text { Base }=\text { Base }(+ \text { Derivational Suffix })
$$

Because the rule is recursive, it allows for a base to be followed by any number of derivational suffixes.

\subsection{Corollary scope rule}

Informally, we may observe that suffixes - inflectional as well as derivationalsemantically PERTAIN to the bases to which they are added. Moreover, when suffixation is recursive, each new suffix pertains semantically to all and only the 


\section{Anthony C. Woodbury}

base to which it is added: not to a part of the base, nor (except in the case of inflection) to a whole phrase. It is fair to say that this is a basic assumption about morphology, although it is only sometimes made explicit, whether as something absolute (e.g., DiSciullo and Williams 1987), or as a default that helps us explain to ourselves the 'weirdness' of cases which violate it somehow (e.g., Baker 1985, Sadock 1991). Let us formulate it as follows:

\section{(18) Corollary scope rule}

A suffix is an operator or modifier with scope over exactly the base to which it was added.

It should be clear, for example, that (18) describes well the semantics evident in (14)-(16), and that it may serve as a transparent interpretive corollary for the formational rules in (13) and (17).

\section{The orthodoxy of suffixation}

How do suffixation and the corollary scope rule just described amount to a 'morphological orthodoxy'? Suffixation is prolific; it is (virtually) the only process in the morphology; and it has been stable and persistent throughout the Yupik-Inuit family and even Eskimo-Aleut. Let us take each point in turn.

\subsection{Suffixation is prolific}

This is the case, first, in the sense that there are many productive suffixes. In Jacobson's (1984) dictionary of Central Alaskan Yupik (which includes Cup'ik as one of its varieties), there are listings for about 300 possible inflectional endings for ordinary nouns, 1200 for ordinary transitive verbs, and about 500 derivational suffixes.

Suffixation is also prolific in that it is used liberally. According to Jacobson (1984:423), a CAY word may have up to six derivational suffixes but rarely more; Central Siberian Yupik has a lesser tendency toward suffixation than CAY (de Reuse 1994:53); while of West Greenlandic, Fortescue (1984:313) writes, "up to ten or more affixes in succession before the inflectional ending is not particularly unusual - at least in the written language".

We get a crude but effective sense of this simply by observing the sheer bulk of the words in an excerpt of ordinary conversational text from Cup'ik, in which productive derivational affixes are italicized: thus, what precede them are simple bases and what follow them are inflectional endings. Most inflected words in the passage have at least one derivational suffix, and many have two or three ('=' marks enclitic particles, which we can think of as separate syntactic words):
A: Aukwaawaq taw' apc-artu-1lrania, atur-yug-luk' erne-rpak, aki-lir- luku taw' pi-sqe-lluku; Aki-lir-ciq-aa=gguq; Qessa-ngait-uq; El- pet=llu taw' qaner-ya-urr-luten. Qaaggem?

B: Qessa-it-ni-aqami qa? 
A: Qessamka-u-qapiare-yaaq-uq.

B: Maqi-yug-luni taw' qeya-mluarer-tuq. Qeya-ura-qer-luni=1l' ua=i, qessa-it-ni-aqami taw'. Qessa-yugnai-pallaare-naur-tuq. Qessamka- $u$ yaaq-uq. $<\mathrm{NAME}>=$ am, $<\mathrm{NAME}>-\mathrm{m}$ qetunra-a,

A: Qessamka- $u$-qapiara-lria=gguq=gga taw' pi-ngraatni=1l' nii-cuu-nani. Kin-kut ellime-llratni mer-taa-sqe-lluku. Nanra-lli-a=gguq qessa-it-niluku; Ellime-qar-aqan=1l', qessa-yuit-ni-luku. Cali.

A: Cali. Qessa-yuit-ni-luku.

C: Al' pi-ani=gguq, kevgute-t tegu-luk' ag'-uq.

A: Matarr-luku tawaam u-n' pi-sqe-kumteggu.

C: Kayu-ng-uq=gguq an-u-rqe-lliki.

B: Kayu-ng-ni-kuni tau-m iqairissuu-llugpak keveg-ciq-aa.

\subsection{Suffixation is (virtually) the only process in the morphology}

Exceptions to this are extremely rare across the entire language family. There is no mutation or ablaut. Some languages have innovated isolated nonconcatenative prosodic processes such as final vowel lengthening for certain pragmatic functions, including yes-no question formation in Eastern Canadian Inuktitut varieties (e.g., Harper 1974:12-3), or vocative vowel doubling in Cup'ik (Woodbury 1987:726-8):

Nonvocative
ukut 'there here'
anngaqliq 'eldest brother'
qayaq 'kayak'

Vocative
Ukuut! 'Hey, you here!'
Anngaqliiq! 'Hey, eldest brother!'
Qayaaq! 'Hey, kayak(er)!'

There is just one apparent prefix, $t a-$, which marks demonstratives as distal. In Cup'ik it occurs with just one of the demonstrative bases but in Eastern Inuit, including West Greenlandic (Sadock 2003:67-8), it is somewhat more productive:

\begin{tabular}{|c|c|c|c|}
\hline Proxima & & Distal & \\
\hline massa & 'here, near speaker' & tamassa & 'there, near speaker' \\
\hline affa & 'here, north' & taava & 'there, close by' \\
\hline samma & 'here, far down' & tasama & 'there, far down' \\
\hline kigga & 'here, toward outside' & takkiga & 'there, toward outside' \\
\hline
\end{tabular}

Most surprisingly, given the strongly concatenative cast of Yupik-Inuit morphology, there is no compounding, except in two limited cases. In Cup'ik and one other CAY dialect (Cup'ig, spoken on Nunivak Island), there is a verb base ete- 'to be (at)', used as in (22):
Ene-m
aki-ani
et-ut.
house-REL.SG opposite-LOC.SG+3SGP be-IND.3SGS
'They are at the opposite side of the house.' 
However it is common in Cup'ik and Cup'ig, and obligatory in the rest of CAY, to compound the already-inflected head of the associated locative phrase with ete-, which is then subject to further suffixation:

Ene-m aki-an-et-ut.

house-REL.SG opposite-LOC.SG+3SGP-be-IND.3PLS

'They are at the opposite side of the house.'

For Cup'ik this seems a clear case of lexically-governed postlexical or postinflectional compounding. But for the dialects not allowing examples like (22) with uncompounded ete-, the compounding process is only a relic.

Another case of postlexical or postinflectional compounding-if one considers this compounding at all-is that of enclitic particles (Cup'ik, from (19) above):

aki-lir-ciq-aa=gguq

money-provide-FUTURE-IND.3SGA.3SGO=it.is.said

'he will pay him, it is said'

$=g g u q$ 'it is said' is one of a handful of enclitic particles which forms a stress domain with the already-inflected word to which it is added (Woodbury 2002:8996).

These limited postinflectional cases are the only cases of compounding. What never occurs at all is the preinflectional base-base compounding common in English and most other languages.

Thus, aside from a few prosodic modifications, one prefix, and limited postlexical compounding, the morphology is confined to suffixation.

\subsection{Suffixation is historically stable and persistent}

The Yupik-Inuit (or Eskimo) protolanguage is estimated at roughly several thousand years old; proto-Eskimo-Aleut at several thousand more (Woodbury 1984, Fortescue et al. 1994, Bergsland 1989). The corollary scope rule, the inflection rules (13), and the rule of derivation (17) hold for all modern YupikInuit languages and (except for some postlexical verb-auxiliary verb compounding) Aleut as well. The number, person, and case categories and agreement patterns are the same throughout Yupik-Inuit, and are marked with cognate formatives; the mood categories are also very similar (though not always directly cognate: see Bergsland 1951, 1989); and as already noted, suffixation is virtually the only process in the morphology.

A powerful further indication of historical stability is that derivational suffixes are almost never the 'grammaticalizations' of historical bases compounded with other bases (ete- 'to be at', if it is on its way in (22)-(23) to becoming a suffix, is the rare exception). That is, suffixes are cognate with other suffixes across the family, not with bases. Thus in Fortescue et al. (1994)'s extensive comparative 
dictionary of Eskimo, modern bases in the daughter languages are reconstructed as bases in Proto-Eskimo, not as suffixes; and modern suffixes are reconstructed as suffixes, not as bases. This even extends to proto-Eskimo-Aleut, with just a few exceptions.

\subsection{Conclusion so far}

Suffixation is the pervasive, and (virtually) exclusive technique of the morphology. It has maintained itself as such at least from the time of ProtoEskimo-Aleut into all attested daughter languages. It is this that $\mathrm{I}$ term MORPHOLOGICAL ORTHODOXY.

If Eskimo-Aleut, with its pervasive suffixation, is at one typological extreme of morphological orthodoxy, then we must count Chinese-with liberal compounding but nearly no affixation - as at the other. Furthermore, both extremes stand in contrast to MORPHOLOGICALLY HETERODOX families like Indo-European or Algonkian, which partake liberally of compounding, of affixation, and of nonconcatenative morphological processes.

\section{The 'work' of suffixation}

It should be no surprise that suffixation does a lot of 'work' in Yupik-Inuit in the sense that many of the functions encoded by suffixation there are encoded by other means in other languages. This section gives a very brief sketch of the situation in CAY, setting the stage for our investigation into the relationship of some of this 'work' with violations of the corollary scope rule (17). The reader can refer to Jacobson (1984) and Woodbury (1981) for documentation of the specific CAY suffix meanings referred to below (or Badten et al. 1987 for Central Siberian Yupik or Fortescue 1983 for the Inuit varieties, since these functions are common throughout the family):

The work of pronouns. Done by person-and-number-of-possessor marking in noun inflection; person-and-number-of-core-arguments marking in verb inflection.

The work of case particles and adpositions. Done by case marking in noun inflection.

The work of illocutionary particles, subordinating conjunctions and complementizers. Done by mood marking in verb inflection.

The work of lexical and auxiliary verbs. Done by noun-to-verb derivational suffixes, including the only forms in the language for 'have', 'be', 'be at', and 'get'; also forms for relatively concrete meanings like 'eat', 'hunt', 'make', 'hit someone in (body part noun)', 'have a messy (NOUN)', 'suffer from (NOUN)', and 'smell strongly of (NOUN)'.

Also done by verb-to-verb derivational suffixes, including forms for argument-structure affecting notions like 'be easy to', 'let', 'ask/tell to', 'say that', 'wait for (SOMEONE) to', 'be time to', '(VERB) in place of'; such modal meanings as 'try to' 'want to', 'be about to', 'plan to'; and aspect or time-related meanings like 'be in a state of (VERB)-ing', 'become', 'begin to', 'not have (VERB)-ed yet', and '(VERB) late'. 
The work of nouns, quantifiers and specifiers. Done by verb-to-noun derivational suffixes, including forms for 'device for (VERB)-ing', 'place for (VERB)-ing', 'time of (VERB)-ing', and 'extent of (VERB)-ing'.

Also done by noun-to-noun derivational suffixes, including forms for 'abundant', 'bit of', 'a few lousy (NOUN)-s', 'supply of', 'inhabitant of', 'relation as (KIN NOUN)', 'one who is similar to (NOUN)', and 'owner of'.

The work of adjectives. Done by noun-to-noun derivational suffixes, including (often the only) forms for 'new', 'good', 'old', 'large', 'small', 'darned', 'genuine', 'poor substitute for (NOUN)', and 'early (TIME NOUN).'

Also done by verb-to-verb derivational suffixes, including forms whose effect is to modify the meaning of the subject of the verb such as 'poor (SUBJECT) does (VERB)' and 'darned (SUBJECT) does (VERB)'.

The work of adverbs. Done by verb-to-verb derivational suffixes, including forms for temporal meanings like 'now and then', 'late'; for propositional attitude meanings like 'evidently', 'contrary to expectation', 'probably'; manner meanings like 'poorly', 'happily', 'well', 'easily', 'roughly', 'quickly'; and degree meanings like 'more and more', 'excessively', 'barely'; negatives like 'not', 'will not', and 'never'.

\section{Thesis}

With the extent of 'work' done by suffixation now in mind, let me state my thesis:

(25) Anomalies, 'glitches', and other special qualifications of the rules for inflectional and derivational suffixation ((13) and (17)) and of the corollary scope rule (18) are referred to the grammatical or semantic content of individual suffixes, in keeping with the behavior associated with that content in languages with more heterodox morphology and syntax.

In what follows I will take up three such anomalies: noun-to-verb derivational suffixes whose scope anomalies recall characteristics of $\mathrm{N}+\mathrm{V}$ compounding or 'noun incorporation' (Sec. 5); verb-to-verb suffixes whose scope anomalies recall characteristics of the syntax and semantics of complement-taking verbs (Sec. 6); and word-internal verb-base ellipsis whose formational anomalies recall syntactic gapping (Sec. 7).

\section{Noun-to-verb derivational suffixes with $\mathbf{N}+\mathrm{V}$ compound (noun incorporation) properties}

As noted in Sec. 3, CAY (and all Yupik-Inuit) has noun to verb derivational suffixes which do the 'work' of nominal complement taking verbs. (26) lists eight of the 85 or so productive noun to verb suffixes in Cup'ik (see Woodbury 1981:349-485; Jacobson 1984), illustrated with examples in (27): 
(26)

NOUN-ngu-
NOUN-ngqerr-
NOUN-ngite-
NOUN-tur-
NOUN-lngu-
NOUN-li-
NOUN-yag-
NOUN-cugninarqe-

(27)

$$
\begin{aligned}
& \text { kitu-u-yit? } \\
& \text { qaya-ngqer-tua } \\
& \text { pilugupi-it-ua } \\
& \text { taryaqvag-tur-tua } \\
& \text { citegta-lngu-unga } \\
& \text { en-li-unga } \\
& \text { cug-yag-tuq } \\
& \text { puyur-cugninarq-uq }
\end{aligned}
$$

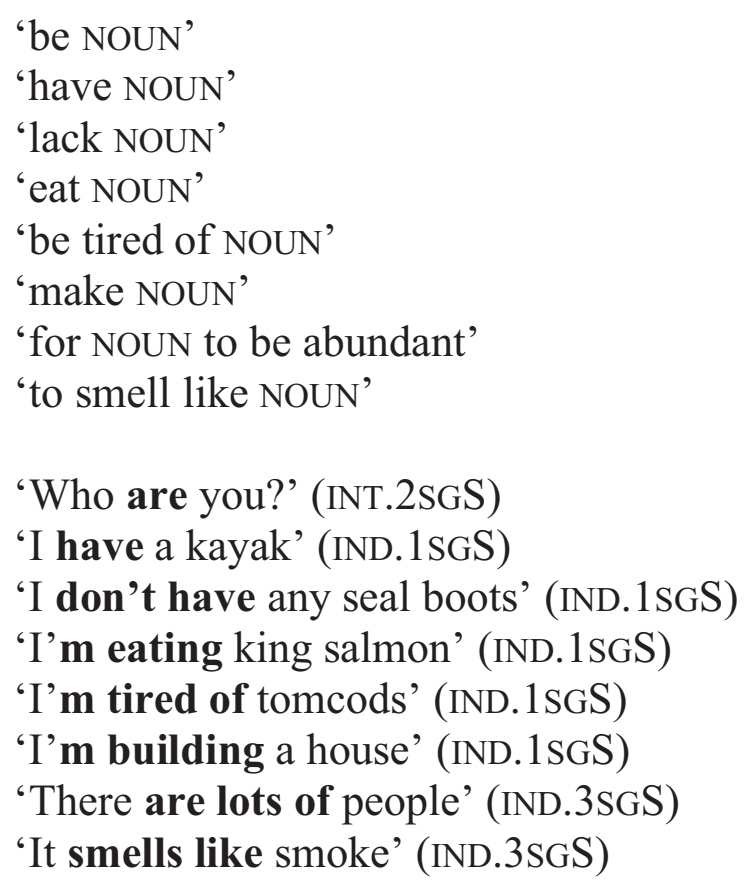

These suffixes enter into a construction that presents a class of systematic anomalies for the corollary scope rule (18):

(28) Ene-ngqer-tua.

house-have-IND.1SGS

'I have a house/houses.'

(29) Ciku-meng atauci-meng ene-ngqer-tua. ice-MOD.SG one- MOD.SG house-have-IND.1SGS 'I have one house made of ice.'

Semantically, the base ene- 'house' is construed as the head of a noun phrase that is modified by two entirely independent inflected nouns in the modalis case, i.e., 'one house made of ice'. Moreover, the modalis case is an appropriate case for syntactically independent indefinite direct objects and other verbal complements, as shown in (30), where ene- 'house', with its coconstituents ciku- 'ice' and ataucir- 'one', is the indefinite direct object of the inflected verb base tangerr- 'see':

$$
\begin{array}{llll}
\text { En-meng ciku-meng } & \text { atauci-meng } & \text { tanger-tua. } \\
\text { house- MOD.SG ice- MOD.SG } & \text { one- MOD.SG } & \text { see- IND.1SGS } \\
\text { 'I see one house made of ice.' } &
\end{array}
$$

The corollary scope rules appears to be violated in (29) because while -ngqerr- 'have' has scope over the whole base ene- 'house', it also has scope over the external modifiers of that base, namely ciku- 'ice' and ataucir- 'one', despite 


\section{Anthony C. Woodbury}

their syntactic independence as inflected words. Also apparently violated is the lexicalist hypothesis (see DiSciullo and Williams 1987 and others before them), which rules out derivational processes which refer to syntactic phrases, and syntactic constituency relations among parts and subparts of words.

Sadock $(1980,1985)$, in an effort to challenge the lexicalist hypothesis, pointed out parallels between West Greenlandic constructions like (29), and noun incorporation constructions in Iroquoian languages and in Southern Tiwa, terming all as 'noun incorporation'. For these constructions, he argued that a morphological principle bound the head noun with a governing verbal element, while a different - and mismatching - syntactico-semantic principle treated the noun head and its modifiers as a single NP complement to the governing verbal element. $\mathrm{He}$ used the term 'noun incorporation' - traditionally used to describe the noun-basewith-verb-base compounding that was the hallmark of the construction in Iroquoian and Southern Tiwa.

Despite the functional parallelism, Mithun (1984, 1986)-echoing Sapir (1911) - argued that only N+V compounding, not Yupik-Inuit type suffixal derivation, constituted true noun incorporation, adducing as well some functional differences.

It is indeed interesting whether the syntactico-semantic ramifications of $\mathrm{N}+\mathrm{V}$ compounding are necessarily different from those of noun-to-verb derivation. Nevertheless, the degree to which they are similar is very striking and worthy of an account, especially since - apparently - the more we learn about each of them, the more parallels we find.

For example, CAY allows what has been called a DOUBLING construction, as in the following Cup'ik text example:

$$
\begin{aligned}
& \begin{array}{l}
\text { Qalqapa-paarrlug-meng } \\
\begin{array}{l}
\text { axe-huge- MOD.SG } \\
\text { axe-have-PAST-alas!-APO.1SGS }
\end{array}
\end{array} \\
& \begin{array}{l}
\text { eqiurr-suute-pigar-meng } \\
\text { then }
\end{array} \\
& \begin{array}{l}
\text { chop-device.for-real- MOD.SG bearable.weight-lack-one.which- MOD.SG } \\
\text { 'I did (alas!) once have an axe, a huge axe; a real chopper (sc, sharp), a } \\
\text { heavy one.' }
\end{array}
\end{aligned}
$$

Here, there are multiple, loosely-slung modalis-case modifiers for qalqapag'axe', the base in the scope of -ngqerr- 'have'. But note that among them is qalqapapaarrlugmeng 'huge axe', repeating the very noun base it seems to modify.

It turns out that such doubling is possible as long as the internal noun base is not more referentially specific than the external NP. Thus (32), like (31), is fine; but (33), where the noun base can'giirar- 'blackfish' is more specific than neqe'fish' is ruled out: 
can'giira-neng neqe-ngqerr-ameng. blackfish-MOD.PL fish-have-CONSEQ.3REFL.PLS 'when they have fish, blackfish'

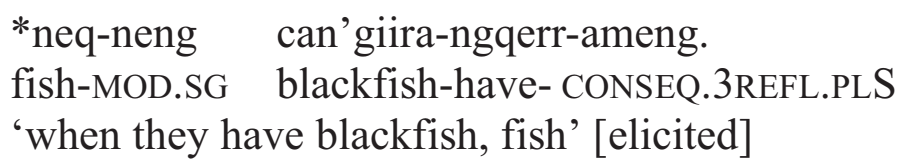

According to Sadock (1985), doubling is ruled out in West Greenlandic; and in that respect, he argues, West Greenlandic is like Southern Tiwa, which also allows stranding but rules out doubling in its $\mathrm{N}+\mathrm{V}$ compounding construction. Yet doubling is a hallmark of Iroquoian incorporation, where it is shown to place precisely the same requirements on the relative specificity of the internal and external noun copy, so that the internal copy functions as a classifier to which the external copy may add specificity (H. Woodbury 1975). ${ }^{2}$ Thus, variations among the Yupik-Inuit languages in their treatment of noun-to-verb derivational suffixes emulates the variation we also find among $\mathrm{N}+\mathrm{V}$ compounding systems.

Apparently, once affixes have meanings typical of verb bases in most other languages, they pick up syntactic characteristics like the ability to govern complex NP complements. Even more, since they co-occur in the same word with a noun, they pick up the morphosyntactic and semantic characteristics of $\mathrm{N}+\mathrm{V}$ compounds. This seems to me the phenomenon to be noted and explained, much more so than the obvious and evident structural distinction between affixal derivation and compounding. For here, function seems to trump structure.

\section{Verb-to-verb suffixes with complement-taking-verb properties}

We now turn to a second case. Like the first one, it involves derivational suffixes which do the 'work' of complement-taking verbs; but in this case the complements are not nominal but verbal or clausal, and the suffixes - which derive verbs from verbs - have meanings like 'say,' 'think,' 'tell,' and 'cause'.

\subsection{Basic examples}

Kleinschmidt (1851) identified a set of West Greenlandic suffixes which, when added to a verb base, added an agent argument as a relative case subject, while preserving as non-subjects the original base's absolutive and (if any) relative case arguments. He called them DOUBLE TRANSITIVE suffixes. The following is a list of

\footnotetext{
${ }^{2}$ Rosen (1989:308) suggests that West Greenlandic constructions with stranding as in (29) are covert classifier-incorporation structures too, only with a null-headed external NP. While this is consistent with the facts in some cases, it isn't in all cases because a null-head reading is not always available. So, on this hypothesis, (29) would mean something like 'I house-made one [NULL-HEAD] made of ice'. However, if we test this in (30) by deleting enmeng 'house-MD.SG', the result means 'I see one piece of ice' and not 'I see one [NULL-HEAD] made of ice' or 'I see something made of ice.'
} 
major double transitive suffixes in Cup'ik (discussed in Woodbury 1985, Jacobson 1984, 1995):

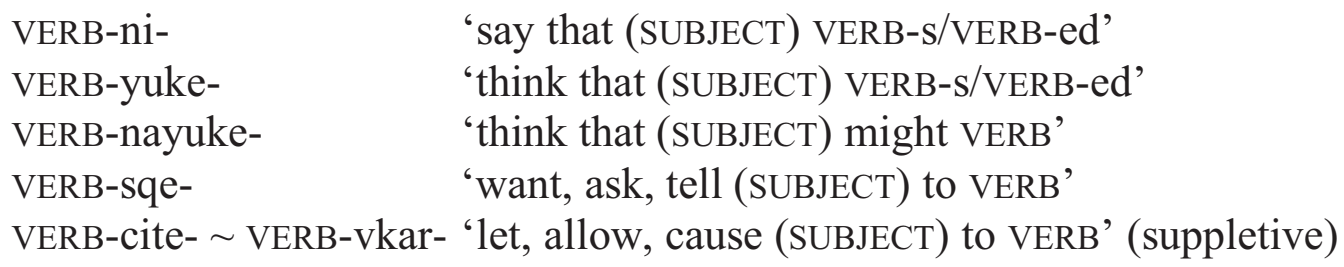

To see how this works, consider these examples, respectively, of inflected intransitive and transitive verb bases (examples from Woodbury 1985):

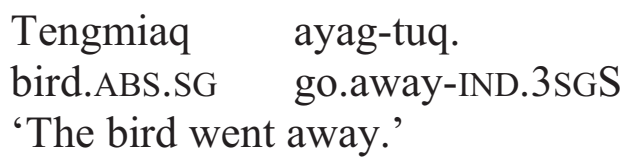

(36) Tan'gurraa-m tengmiaq ivar-aa.

boy-REL.SG bird. ABS.SG seek-IND.3SGA+3SGO

'The boy looked for the bird.'

Then, when the suffix -cite- $\sim$-vkar- 'let, allow, cause (SUBJECT)...' is added, a new letter/allower/causer subject can be expressed:

$$
\begin{array}{lll}
\text { Liissa-m } & \text { tengmiaq } & \text { ayag-cit-aa } \\
\text { Lisa- REL.SG } & \text { bird. ABS.SG } & \text { go.away-let-IND.3SGA+3SGO } \\
\text { 'Lisa let/made the bird go away. " }
\end{array}
$$

$$
\begin{aligned}
& \text { Liissa-m tengmiaq tan'gurrar-mun ivar-cit-aa } \\
& \text { Lisa-REL.SG bird. ABS.SG boy-TERM.SG seek-let-IND.3SGA+3SGO } \\
& \text { 'Lisa let/made the boy look for the bird.' }
\end{aligned}
$$

By the corollary scope rule (18), the double transitive suffix has scope over the entire base to which it is added. This is seen in recursive stages, in keeping with the derivational suffixation rule (17), in the following two text examples. Each contains two double transitives, -cite- $\sim$-vkar- 'let, allow, cause (SUBJECT)...' and -ni- 'say that (SUBJECT)...':

(39) Ekucir -ciss -ngait -ni -luta

Pay.fare -let/make -will.not -say -APO.1PLO

'Saying (he) will not make us pay any fare'

(40) nulirqe -vkar -ciq $\quad$-ni $\quad$-luku

marry -let/make -will -say $-\mathrm{APO} .3 \mathrm{SGO}$

'Saying (he) will let him marry' 
But (17) and (18) do not tell the whole story. In particular, they do not explain why there are some key differences in combinatoric potential even among the major double transitive suffixes listed above.

\subsection{Differences in the embedding of tense}

One such difference concerns tense-marked verb bases: of the suffixes in (34), just -ni- 'say that (SUBJECT)...' and -yuke- 'think that (SUBJECT)...' can combine with tense-marked bases, that is, bases ending with tense suffixes like -llru'PAST', -ciqe- 'FUTURE', -qatar- 'be about to...' or -ngaite- 'will not'. This can be seen in (39)-(40), where -ni- 'say that (SUBJECT)...' follows -ngaite- 'will not' and -ciqe- 'FUTURE', respectively. It can also be seen in (41)-(42), which, along with (39)-(40), occur in a body of transcriptions of about 20 hours of Cup'ik narrative and conversation (supplemented with several Yup'ik examples from Jacobson):

(41) Examples with -ni- 'say that (SUBJECT)...'

Naulluu-llru-ni-uq, 'he says he was ill' (Jacobson 1995:324)

pirpa-k-tu-llru-ni-luku, 'saying he always had good (weather)'

tangerr-lug-naq-saaqe-ciq-ni-luku, 'saying he will tend to look poorly'

pic-uic-aaqe-ciq-ni-luku, 'saying he will tend not to catch game'

aqva-ciq-ni-lukek, 'saying (he) will fetch those two'

nakaciu-qatar-ni-luki, 'saying they are going to have a Bladder Festival'

mer-tar-vi-ur-ciiq-ni-yuk-aq-aqa, 'I thought (they) said it will be a place for getting water'

(42) Examples with -yuke- 'think that (SUBJECT)...'

Tuqute-llru-yuk-luki, 'thinking (he) killed them' (Jacobson 1995:326)

Aya-llru-yuk-aa, 'he thinks he (someone else) went' (Jacobson 1984:599)

Maqi-ya-qatar-yuk-luku, 'he was thinking of going to take a firebath'

By contrast, there are no examples in the Chevak corpus, or in other sources that I know of, of tense-marked bases combining with the other three double transitives listed in (34), namely:

$$
\begin{aligned}
& \text { VERB-nayuke- 'think that (SUBJECT) might VERB' } \\
& \begin{array}{l}
\text { VERB-sqe- } \\
\text { VERB-cite- } \sim \text { VERB-vkar- 'let, allow, cause (SUBJECT) to VERB' (suppletive) }
\end{array}
\end{aligned}
$$

The account that I wish to offer is simply this: the semantics of -ni- 'say that (SUBJECT)...' and -yuke- 'think that (SUBJECT)...' allows for the embedding of a complete proposition, including tense; whereas the semantics of the suffixes in (43) includes specification of an unrealized modality for the embedded proposition in place of tense. In English, this same property of 'say' and 'think' is handled syntactically, by the device of that-complementation with verbs say and think, which allows for the expression of embedded-clause tense. Notice that this 


\section{Anthony C. Woodbury}

account is in violation of the corollary scope rule in (18) since it extends the scope of tense (and hence also the double transitive suffixes) to constituents outside of the immediate bases to which they are attached. ${ }^{3}$

This account also allows us to explain another fact. - $n i$ - 'say that (SUBJECT)...' and -yuke- 'think that (SUBJECT)...' are recursive to a degree greater than other suffixes in that they start verbal derivation over again. Thus, for example, it is possible for two tense markings to occur if and only if one of these two suffixes has occurred, e.g.:

$$
\begin{aligned}
& \text { atanqe -ciq -ni } \quad \text {-llru }- \text { ateng amani. } \\
& \text { Wait.for -FUTURE -say -PAST -CONSEQ.3SGA+3REFL.PLO there } \\
& \text { 'Because he said (he) will wait for them there' }
\end{aligned}
$$

$$
\begin{aligned}
& \text { Naulluu -llru -ni -llru -uq. } \\
& \text { be.ill -PAST -say -PAST -IND.3SGS }
\end{aligned}
$$

'He said he was ill.' (Jacobson 1995:324)

This is possible, however, if tense is allocated per (semantically) embedded clause.

\subsection{A (familiar) anomaly in the embedding of negation}

The double transitives also differ with respect to the embedding of bases negated with -nrite- 'not' or -ngaite- 'will not', (which combines tense and negation). The same two suffixes that could combine with tense-marked bases can combine with negation-marked bases; but they are joined by a third, -nayuke- 'think that (SUBJECT) might...' (which, following our observations in Sec. 6.2, can only occur with the untensed -nrite- 'not' and not the tensed -ngaite- 'will not'). Thus:

Examples with -ni- 'say that (SUBJECT)...'

Nuli-q-ngait-ni-luku, 'saying (he) will not have her as a wife' tekiy-ngait-ni-lun', 'saying he (himself) will not arrive' makuu-vkar-ngait-ni-luku, 'saying he will not let it be this kind'

(47) Examples with -yuke- 'think that (SUBJECT)...'

Qacingqa-nri-cuk-luki, 'thinking they were not staying put' Atur-ngai-cuk-luku, 'thinking you will not encounter it'

(48) Examples with -nayuke- 'think that (SUBJECT) might...' Niite-nrit-nayuk-luku, 'thinking (they) might not hear him' Keg-qa-nrit-nayuk-luku, 'thinking (they) might not just bite him'

\footnotetext{
${ }^{3}$ Although even here, the corollary scope rule is problematic since the suffix also has scope over the terminalis case notional subject of the embedded verb base. See Woodbury and Sadock (1986) for demonstration and discussion.
} 
This free occurrence of negation contrasts with restrictions on negation with -sqe- 'want, ask, tell (SUBJECT) to...', with which negation must occur 'outside' the embedded base, i.e., after -sqe- (here - vke- is a suppletive allomorph of -nrite'not'): ${ }^{4}$

Examples with -sqe- 'want, ask, tell (SUBJECT) to...'

Anuqe-gguire-sqe-vke-naki, lit: 'not telling (them) to pass to windward of them' (entails: 'telling them not to pass to windward of them')

Pekte-sqe-vke-naki, lit: 'not telling (them) to walk (entails: 'telling them not to walk')

Inangli-sqe-vke-nata, lit: 'not telling us to go to bed' (entails: 'telling us not to go to bed')

Kinerci-qaa-sqe-vke-naki, lit: 'not telling him to dry them' (entails: 'telling him not to dry them')

This is, of course, the familiar NEG-RAISING pattern found for verbs like want in English, where I don't want him to come, with negation 'outside' want, nevertheless entails 'I want him not to come'. Note however that English does not have this entailment so clearly with say to, cf. I didn't say to come vs. I said not to come. In any case, the pattern that we find is another violation of the corollary scope rule (18) which can be explained in terms of its emulation of a crosslinguistically wide-spread pattern associated with its semantic function: in this case, the neg-raising pattern common with 'want' and 'say to' complementation. If this is right as a general matter, then we may well find considerable further correspondence between the grammar of productive Yupik-Inuit word-internal suffixes with meanings like 'say', 'think', and 'tell', and that of their independentword cousins in languages with less synthesis.

\section{Verb base ellipsis in Tarramiut Inuktitut}

We now turn to our third case, which concerns rules (13) and (17), which ensure that every word begins with a base, to which derivational and then inflectional suffixes may be added. This base-first principle is especially robust because the base lexicon and the suffix lexicon are disjunct in all Yupik-Inuit languages: that is, there are no elements which function sometimes as a base, and other times as a suffix.

The following from Cup'ik bear this out: none are good because the beginning element in each case is a suffix and not a base:

\footnotetext{
${ }^{4}$ This allomorph occurs with the subordinative mood marker -na-, which itself is a suppletive allomorph of the normal subordinative marker -lu-, triggered by -nrite- and other etymologically stative suffixes ending in -ite-. Of course, one might simply take this as meaning that CAY has innovated a negative subordinative mood in -vkena-, a conclusion which in no way changes the scopal arguments being advanced here.
} 


\section{Anthony C. Woodbury}

$(50)$

$\begin{array}{ll}\text { *li-uq } & \text { 's/he made (something)' (IND.3SGS) } \\ \text { *yugnait-uq } & \text { 's/he definitely didn't' } \\ \text { *llini-uq Peter-aq } & \text { 'Peter evidently did' }\end{array}$

Instead, all Yupik-Inuit languages have an 'empty' base $p i$-, which means 'thing' when functioning as a noun, and 'do' when functioning as a verb. Using $p i$ - as the base, it is possible to 'support' suffixes like those in (50):

$$
\begin{array}{ll}
\begin{array}{ll}
\text { pi-li-uq } \\
\text { pi-yugnait-uq }
\end{array} & \text { 's/he made it/one' (IND.3SGS) } \\
\text { pi-llini-uq Peter-aq } & \text { 's/he definitely didn't' } \\
\text { 'Peter evidently did' }
\end{array}
$$

In this way, it is possible to make use of the lexical content of suffixes, even in the absence of a specific, concrete base, and still obey the rules in (13) and (17).

However, Swift and Allen (2002) document a unique innovation in Tarramiut Inuktitut which violates the normal rules by allowing suffixes word-initially:
Anaana qajur-tu-ruma-junga.
mother soup-consume-want-PARTICIPLE.1SGS
(Elijah 2;5)
'Mother, I want to have soup.'
0-Nia-lir-qutit
ZERO.BASE-TODAY.FUT-INGRES-IND.2SGS
'You will [have soup] later today.'

$\begin{array}{lll}\text { Qajur-tu-nia-lir-qutit } & \text { siaru. } & \text { (Full form) } \\ \text { soup-consume-TODAY.FUT-INGRES-IND.2SGS } & \text { later } & \\ \text { 'You will have soup later today.' } & \end{array}$
siaru. (Elijah's mother) later

On their analysis, the word-initial suffixes follow an implicit ZERO VERB BASE which can be reconstructed from the discourse context: thus in the mother's response in (52), the (complex) base meaning 'consume soup' is cued in the child's request. They conclude that:

...postbases [i.e., derivational suffixes] with certain meanings are prevalent in elliptical structures, specifically temporal, modal, politeness, and negation. These postbases fall into semantic categories often associated with auxiliaries cross-linguistically, and many of them make clear contributions to the meaning of an existing structure, e.g., -guma'want to', -qajaq- 'be able to', -si- 'be about to', and -nngit- 'not'. However, it is not clear whether these characteristics contribute to the prominence of these postbases in elliptical structures by for example, rendering them more analyzable than other postbases. (p. 154) 


\title{
Morphological Orthodoxy in Yupik-Inuit
}

Even taking into account their caution about triggering predicate meanings, what is very clear is that this is a morphologically embedded instance of the GAPPING pattern found on a syntactic level in English and other languages.

One difference between this phenomenon, and the two preceding ones is that this one undermines not only the corollary scope rule-the CONSTRUAL of morphological structure - but also the morphological structure itself. That is, verb base ellipsis loosens morphological orthodoxy in a way which undermines the notion of suffixation. For whatever reason, such loosening of structure is extremely rare in Yupik-Inuit, given such a strict historical disjunction between the base and suffix lexicons.

\section{Conclusions}

Given the large amount of 'work' done by suffixation in Yupik-Inuit, I hope it will be productive to use anomalies, 'glitches', and other special qualifications of the rules for inflectional and derivational suffixation ((13) and (17)), and of the corollary scope rule (18), as a heuristic for finding further instances in the family of universally-attested semantic and syntactic phenomena: the three examples given seem only to scratch the surface.

More broadly, it would be worth exploring other language families with persistently orthodox or rigid morphological structure-whether pervasivelysuffixing like Yupik-Inuit, pervasively compounding like Chinese, or some other radical type - in order to understand better the extent and the limits of structure; as well as the influence on structure of meaning and function. It seems to me that Sapir (1921) was grappling with this same set of issues when he wrote the following somewhat enigmatic set of passages:

\begin{abstract}
We may put the whole matter in a nutshell by saying that the radical and grammatical elements of language, abstracted as they are from the realities of speech, respond to the conceptual world of science, abstracted as it is from the realities of experience, and that the word, the existent unit of living speech, responds to the unit of actually apprehended experience, of history, of art. The sentence is the logical counterpart of the complete thought only if it be felt as made up of the radical and grammatical elements that lurk in the recesses of its words. It is the psychological counterpart of experience, of art, when it is felt, as indeed it normally is, as the finished play of word with word. (p. 33)
\end{abstract}

The best that we can do is to say that the word is one of the smallest, completely satisfying bits of isolated 'meaning' into which the sentence resolves itself. (p. 35)

Such features as accent, cadence, and the treatment of consonants and vowels within the body of a word are often useful as aids in the external demarcation of the word, but they must by no means be interpreted, as is sometimes done, as themselves responsible for its psychological existence. They at best but strengthen a feeling of unity that is already present on other grounds. (p. 36)

The fascinating questions raised by looking at matters this way seem to me to transcend contentious, all-or-nothing positions on whether it is structure or function that supremely determines natural languages. 
Anthony C. Woodbury

\section{References}

Anderson, Stephen R. 1982. Where's morphology? Linguistic Inquiry 13: 571612.

Anderson, Stephen R. 1992. A-Morphous morphology. Cambridge Studies in Linguistics 62. Cambridge: Cambridge University Press.

Badten, Linda Womkon, Vera Oovi Kaneshiro, Marie Oovi, and Steven A. Jacobson. 1987. A Dictionary of the St. Lawrence Island / Siberian Yupik Eskimo Language. Fairbanks: Alaska Native Language Center, University of Alaska.

Baker, Mark. 1985. The mirror principle and morphosyntactic explanation. Linguistic Inquiry 16: 373-415.

Bergsland, Knut. 1951. Kleinschmidt Centennial IV: Aleut demonstratives and the Aleut-Eskimo relationship. IJAL 17: 167-79.

Bergsland, Knut. 1989. Comparative aspects of Aleut syntax. Journal de la société finno-ougrienne 82: 7-80.

Bergsland, Knut. 1997. Aleut Grammar. Research Paper No. 10. Fairbanks: Alaska Native Language Center, University of Alaska.

de Reuse, Willem J. 1994. Siberian Yupik Eskimo: The Language and its Contacts with Chukchi. Studies in Indigenous Languages of the Americas. Salt Lake City: University of Utah Press.

DiSciullo, Anna-Maria, and Edwin Williams. 1987. On the definition of the word. Linguistic Inquiry Monograph 14. Cambridge: MIT Press.

Fortescue, Michael. 1983. A Comparative Manual of Affixes for the Inuit Dialects of Greenland, Canada, and Alaska. Meddelelser om Grønland, Man and Society 4. Copenhagen.

Fortescue, Michael. 1984. West Greenlandic. Croom Helm Descriptive Grammars. London: Croom Helm.

Fortescue, Michael, Steven Jacobson, and Lawrence Kaplan. 1994. Comparative Eskimo Dictionary with Aleut Cognates. Research paper No. 9. Fairbanks: Alaska Native Language Center, University of Alaska.

Harper, Kenn. 1974. Some aspects of the grammar of the Eskimo dialects of Cumberland Peninsula and North Baffin Island. National Museum of Man Mercury Series, Ethnology Division, Paper No. 15. Ottawa: National Museums of Canada.

Jacobson, Steven A. 1984. Yupik Eskimo Dictionary. Fairbanks: Alaska Native Language Center, University of Alaska.

Jacobson, Steven A. 1995. A Practical Grammar of the Central Alaskan Yupik Eskimo Language. Fairbanks: Alaska Native Language Center, University of Alaska.

Kleinschmidt, Samuel. 1851. Grammatik der grönländischen Sprache. Berlin. [Reprinted 1968, Hildesheim: Geog Olms.]

Mithun, Marianne. 1984. The evolution of noun incorporation. Language 60: 84793. 
Mithun, Marianne. 1986. On the nature of noun incorporation. Language 62: 3237.

Rosen, S. 1989. Two types of noun incorporation: A lexical analysis. Language 65: 294-317.

Sadock, Jerrold M. 1980. Noun incorporation in Greenlandic: A case study of syntactic word formation. Language 56: 300-319.

Sadock, Jerrold M. 1985. Autolexical syntax: A theory of noun incorporation and similar phenomena, Natural Language and Linguistic Theory 3: 379-440.

Sadock, Jerrold M. 1991. Autolexical Syntax: A Theory of Parallel Grammatical Representations. Chicago: University of Chicago Press.

Sadock, Jerrold M. 2003. A Grammar of Kalaallisut (West Greenlandic Inuttut). Languages of the World / Materials 162. Munich: Lincom Europa.

Sapir, Edward. 1911. The problem of noun incorporation in American languages. American Anthropologist 13: 250-82.

Sapir, Edward. 1921. Language: An Introduction to the Study of Speech. New York: Harcourt, Brace, and Co.

Swift, Mary D. and Shanley E. M. Allen. 2002. Verb base ellipsis in Inuktitut conversational discourse. IJAL 68(2): 133-156.

Woodbury, Anthony C. 1981. Study of the Chevak dialect of Central Yupik Eskimo. Ph.D. dissertation, University of California, Berkeley.

Woodbury, Anthony C. 1984. Eskimo and Aleut languages. In David Damas (ed.) Vol. 5: Arctic, 49-63, in William C. Sturtevant (ed.) Handbook of North American Indians. Washington: Smithsonian Institution Press.

Woodbury, Anthony C. 1985. Marginal agents. Papers from the Parasession on Causatives and Agentivity. CLS 21, part 2, 271-292.

Woodbury, Anthony C. 1987. Meaningful phonological processes: A consideration of Central Alaskan Yupik Eskimo prosody. Language 63(4): 685-740.

Woodbury, Anthony C. 2002. The word in Cupik. In Dixon, R. M. W. and Alexandra Y. Aikhenvald (eds.) Word: A cross-linguistic typology, 79-99. Cambridge: Cambridge University Press.

Woodbury, Anthony C. and Jerrold M. Sadock. 1986. Affixal verbs in syntax: A reply to Grimshaw and Mester. Natural Language and Linguistic Theory 4: 229-44.

Woodbury, Hanni. 1975. Onondaga noun incorporation: Some notes on the interdependence of syntax and semantics. IJAL 41(1): 10-20.

Department of Linguistics

University of Texas

1 University Station B5100

Austin, TX 78712-0198 USA

acw@mail.utexas.edu 